\title{
PRÁCTICAS POLITICAS IDENTITARIAS DE HOMBRES GAY DE LA CIUDAD DE MÉXICO: ENTRE LA TENSIÓN Y LA HETERONORMALIZACIÓN
} Ignacio Lozano-Verduzco Universidad Pedagógica Nacional

\section{RESUMEN}

En este trabajo se analiza el discurso, obtenido a partir de entrevistas a profundidad, de 15 hombres que se identifican como "gay", residentes de la Ciudad de México, con la intención de comprender la manera en que usan su deseo homoerótico y su identidad sexual para llevar a cabo prácticas políticas. Los resultados indican que el acercamiento al activismo gay, feminista y de izquierda permite que los hombres lleven a cabo un proceso de reflexión política con mayor ahínco y conciencia de sus actos. La investigación hizo también evidente la carga emocional que implica el asumir un deseo homoerótico y cómo esta apropiación permite a los hombres cuestionar normas sociales que regulan su deseo y su identidad.

\section{PALABRAS CLAVE}

Identidad, masculinidades, gay, prácticas políticas, queer

\section{ABSTRACT}

In this article, the author analyses the discourse of 15 gay men who reside in Mexico City, obtained through in depth interviews, with the objective of understanding how they use their homoerotic desire and sexual identity to carry out political practices. The results show that involvement in gay, feminist, and left-wing activism allows men to undertake processes of political reflection in a more profound manner and be more conscious of their acts. They also show the emotional burden of assuming their 
homoerotic desire publicly and how this appropiation allows them to question social norms that regulate their desire and identity.

KEY WORDS

Identity, masculinities, gay, political practices, queer 


\section{INTRODUCCIÓN}

En este trabajo pretendo llevar a cabo un análisis sobre la manera en que hombres de distintas edades y generaciones, que radican en la Ciudad de México y que se identifican como gay/ homosexual, ocupan/usan el espacio público, significan los avances políticos del movimiento gay mexicano y cómo se posicionan ante él. Específicamente, analizo la forma en que colocan su identidad como gay en el espacio público haciendo "evidente" u "obvio" su deseo homoerótico y su identidad sexual, a través de prácticas y conductas específicas como tomar a su pareja de la mano, besarlo, acudir a la marcha anual o dar información sobre la comunidad lésbico, gay, bisexual y trans (LGBT).

Retomando a Foucault (1978), para efectos de este trabajo, el deseo se considera como una pulsión (que no persigue fines biologicistas) que a manera de operación repetida, permite al yo constituirse a sí mismo dentro del discurso y con la ayuda de la otredad (a través de procesos de interacción social como la socialización, el diálogo, la endoculturación, etcétera). Es así que el deseo homoerótico existe porque es nombrado $\mathrm{y}$ es nombrado precisamente desde las afueras de los sistemas regidores del género y del sexo de cualquier sociedad y en específico de sociedades occidentales y modernas. En esta lógica, el deseo homoerótico tiene un lugar secundario respecto al deseo heteroerótico: de ahí la dificultad de llevarlo a la arena política a través del espacio público, aquel espacio compartido por la ciudadanía.

Este análisis es resultado de un trabajo de investigación más amplio que realicé entre los años 2010 y 2013. El objetivo de dicha investigación fue identificar, describir y analizar la construcción del sentido de identidad de hombres gay de la Ciudad de México y las experiencias emocionales que acompañan a este proceso. Desde el construccionismo social (Ibáñez, 2004; Pujal i Lombart, 2004) y del interaccionismo simbólico (Blumer, 1998), la identidad es un proceso permanente que requiere el diálogo constante entre el sujeto y sus contextos. Esto implica una interacción de la persona con todos sus contextos, de donde se produce una narración que permite al sujeto comprenderse a sí mismo y percibir y dar sentido a los escenarios sociales en donde se incluye. El proyecto también se interesaba en comprender los aspectos subjetivos y sociales que se juegan en la salud mental de los hombres gay.

Debido a que el objetivo principal del proyecto no consideraba a las prácticas políticas y la dimensión de ciudadanía entre sus fines, la construcción de hipótesis sobre estas categorías se hizo conforme avanzó el trabajo de campo y el análisis. En este sentido, tanto la literatura revisada como los datos cualitativos obtenidos en las entrevistas permitieron suponer que si bien el activismo gay contribuyó a visibilizar las necesidades y las demandas del movimiento y, por tanto, a politizarlo a través de su inclusión en políticas públicas, ha tenido el efecto de esterilizar el deseo homoerótico, precisamente el que detonó al movimiento. Esa esterilización se manifiesta en la heteronormalización de lo gay a través de instituciones heteronormadas, en particular el matrimonio y, de ese modo, congela su identidad y el deseo a partir del cual se construye. 
Con esto en cuenta, fue necesario partir de que los sujetos se construyen en subordinación a las normatividades heteropatriarcales (Kimmel, 2008; List, 2005, 2009; Núñez, 2000，2005; Warner, 1993), desde donde el deseo homoerótico y la transgresión de los estereotipos de género resultan una transgresión fundamental al modelo de masculinidad hegemónica (MMH), pues coloca a los hombres homoeróticos en una jerarquía menor con respecto a otros hombres (Connell y Messerschmidt, 2005; List, 2005, 2009; Lozano y Rocha, 2011; Núñez, 2000, 2005). $\mathrm{Al}$ respecto, el MMH se ha descrito como una serie de características a las cuales aspiran los cuerpos-hombres y que producen una serie de lineamientos para el actuar social, desde cómo son socializados los varones, hasta la manera en que actúan y hacen las cosas. Desde el feminismo, es fundamental comprender que a este modelo lo atraviesa la noción de poder (Amuchástegui, 2006) que permite la subordinación de lo masculino sobre lo femenino. Este poder se reproduce constantemente a través de pactos que fortalecen y perpetúan la dominación masculina (Amorós, 1992). Díaz-Loving, Rocha y Rivera (2007) han encontrado que en México este modelo contiene características como ser rudo, fuerte, valiente, agresivo y productivo, características que además se relacionan con expresiones elevadas de homofobia. De tal manera que, como señala Careaga (2004), la identidad gay es ambivalente y contradictoria, ya que encarna el poder otorgado por el MMH, al mismo tiempo que lo cuestiona y resignifica, debido a que este último rechaza la posibilidad del homoerotismo. Para cumplir con mi objetivo, entrevisté a profundidad a 15 hombres que vivían en la Ciudad de México y se identificaban como gay u homosexual. Contacté a estos hombres a través de redes institucionales, redes sociales y por bola de nieve. El muestreo estuvo guiado por el principio de máxima variación (Flick, 2004), por lo que busqué que todos los participantes, a pesar de que compartían una identidad sexo-genérica particular, difirieran en edad, nivel de estudios e ingresos económicos mensuales, así como que residieran en diferentes partes de la ciudad. Lo anterior, con la intención de obtener datos con distintos puntos de vista e historias de vida sobre el mismo proceso: la identidad gay.

\section{PRECISIONES SOCIO-HISTÓRICOS PARA}

\section{EL PLANTEAMIENTO TEÓRICO-METODOLÓGICO}

La percepción del homoerotismo ha cambiado a lo largo del tiempo y del espacio geográfico, debido a circunstancias políticas, sociales y culturales, por lo que es importante reconocer que la gaydad $^{1}$ que cada individuo adopta, se encuentra permeada por estas situaciones (incluyendo las normas en torno a la sexualidad y al género), y no únicamente por su historia de vida. Por tal motivo, basándome en los análisis de Argüello (2014), Díez (2010), Laguarda (2009) y Salinas (2010), propuse especificar tres grupos de entrevistados dependiendo de la generación ${ }^{2}$ en la que crecieron

1 List (2005) usa el término "gaydad" para referirse a la manera en que los hombres se apropian de su "ser gay".

2 Generalmente, el uso de "generación" remite a la edad de los participantes. Sin embargo, en este proyecto me refiero a espacios temporales del movimiento gay en México. El movimiento tuvo diferente impacto en distintos años y espacios temporales. A partir de este análisis, que se 
y fueron socializados. Autores como Laguarda (2009), Salinas (2010) y De la Dehesa (2010) identifican transformaciones sociales importantes que fueron o dieron como fruto cambios políticos y culturales de relevancia para la militancia y el movimiento gay. ${ }^{3}$ De acuerdo con los análisis de estos/as autores/as, consideré que la primera generación, o generación joven, es aquella que asumió su gaydad desde 2004 hasta el momento actual, teniendo como antecedente que en ese año comenzó una campaña nacional en contra de la homofobia, resultado de un discurso de Derechos Humanos adoptado por Vicente Fox desde su candidatura a la presidencia, y de la Ley Federal Para Prevenir la Discriminación (que dio lugar al Consejo Nacional para Prevenir la Discriminación y a la campaña mencionada) (Díez, 2010).

Previo a este año, ubico dos parteaguas en el movimiento homosexual/gay mexicano. El primero, ocurrido en 1978, cuando un grupo de personas que se identificaron como homosexuales salió de manera organizada y con una agenda establecida a manifestarse públicamente (Díez, 2010; Laguarda, 2009; Monsiváis, 1998). Cabe

presenta en la tabla 1 , construí estos grupos generacionales. 3 Si bien el "movimiento homosexual" ha mostrado diversidad de posicionamientos y demandas, la percepción ha sido de una unión completa del activismo gay. Los pocos textos que encontré al respecto señalan un desarrollo histórico similar. No obstante, en mi trabajo de campo llegué a escuchar a activistas gay que manifestaban cierto desacuerdo por las demandas actuales (específicamente ante el matrimonio igualitario), señalando que en sus inicios durante los años setenta y ochenta, el Movimiento de Liberación Homosexual se oponía a cualquier forma de institucionalización debido a sus efectos normalizadores. Entiendo entonces que el movimiento homosexual es uno hegemónico y que ha minimizado voces disidentes sobre la propia "diversidad sexual". aclarar que esta manifestación política sólo fue posible gracias a la organización comunitaria de un grupo de intelectuales mexicanos (Argüello, 2014). La manifestación pública de un grupo de personas que se autodenominaron "homosexuales" generó efectos mediáticos y sociales importantes. El segundo parteaguas ocurre a inicios de la década de los ochenta, con la llegada de la epidemia del SIDA a México, que significó un obstáculo político para la lucha contra la homofobia y la consolidación del movimiento gay. La negativa de las autoridades sanitarias del país a asumir el VIH como un problema importante significó la organización de hombres homosexuales y mujeres lesbianas, que encontraron aliados/as en algunas personas heterosexuales, y la formación de asociaciones civiles que no sólo fungieron como paliativo para los efectos del VIH, sino también para ejercer presión a las autoridades gubernamentales.

La segunda generación de participantes fue de hombres que asumieron su gaydad entre los años 1985 y 2004, teniendo como telón de fondo a la pandemia de VIH (García, Andrade, Maldonado y Morales, 2009) que, por otra parte, logró consolidar el movimiento (veáse tabla 1). Esta generación también se formó en medio del bullicio de un fuerte discurso global socialista durante el fin de la guerra fría y la caída de la Unión Soviética, y de una crisis económica nacional que benefició a algunos sectores de la sociedad mexicana (Laguarda, 2009). La tercera generación quedó conformada por hombres que asumieron su gaydad desde el nacimiento del movimiento, en 1978, hasta el año 1984. En la siguiente tabla 
resumo hechos importantes en el movimiento gay

mexicano y los efectos políticos y subjetivos que

dieron lugar a esta división generacional. ${ }^{4}$

Tabla 1. Hitos y aspectos en el movimiento gay mexicano y su impacto social y subjetivo

\begin{tabular}{|c|c|c|c|c|}
\hline $\begin{array}{l}\text { Hecho y } \\
\text { periodo }\end{array}$ & $\begin{array}{c}\text { Implicaciones para el } \\
\text { movimiento }\end{array}$ & $\begin{array}{c}\text { Demandas del } \\
\text { movimiento }\end{array}$ & $\begin{array}{c}\text { Incidencia en } \\
\text { políticas públicas* }\end{array}$ & Impacto social \\
\hline $\begin{array}{l}\text { Nacimiento del } \\
\text { movimiento } \\
\text { 1978-1984 }\end{array}$ & $\begin{array}{l}\text {-Visibilización de la } \\
\text { población gay y lésbica } \\
\text {-Organización de la } \\
\text { sociedad civil } \\
\text {-Expresiones artísticas, } \\
\text { culturales y políticas } \\
\text { lésbico-gay } \\
\text {-Demandas por la } \\
\text { igualdad de derecho }\end{array}$ & $\begin{array}{l}\text { Reconocimiento de } \\
\text { la diversidad y del } \\
\text { derecho a la } \\
\text { diferencia }\end{array}$ & Ninguna & $\begin{array}{l}\text {-Rechazo a } \\
\text { identidades } \\
\text { homoeróticas } \\
\text {-Clandestinidad de la } \\
\text { homosocialización }\end{array}$ \\
\hline $\begin{array}{l}\text { Pandemia del } \\
\text { VIH/SIDA } \\
1985-1991\end{array}$ & $\begin{array}{l}\text {-Estigmatización del } \\
\text { homoerotismo } \\
\text {-Aparición de } \\
\text { organizaciones de la } \\
\text { sociedad civil }\end{array}$ & $\begin{array}{l}\text {-Derecho a la salud } \\
\text {-Derechos civiles } \\
\text { para parejas } \\
\text { homoeróticas }\end{array}$ & $\begin{array}{l}\text {-Creación de } \\
\text { CONASIDA } \\
\text {-Modificación de la } \\
\text { Ley General de } \\
\text { Salud }\end{array}$ & $\begin{array}{l}\text {-Patologización y } \\
\text { rechazo a identidades } \\
\text { homoeróticas }\end{array}$ \\
\hline $\begin{array}{l}\text { Consolidación } \\
\text { del movimiento } \\
1992-2005\end{array}$ & $\begin{array}{l}\text {-Reconocimiento del } \\
\text { uso "gay" por hombres } \\
\text { homoeróticos } \\
\text {-Ampliación de } \\
\text { objetivos: sociales y } \\
\text { médicos } \\
\text {-Inicia campaña } \\
\text { nacional en contra de la } \\
\text { homofobia } \\
\text { (CONAPRED) }\end{array}$ & $\begin{array}{l}\text {-Uso de } \\
\text { antiretrovirales } \\
\text {-Reconocimiento a la } \\
\text { diversidad sexual } \\
\text {-Normalización de } \\
\text { identidades lésbico- } \\
\text { gay }\end{array}$ & $\begin{array}{l}\text {-Enfocadas a la } \\
\text { garantía de } \\
\text { derechos de } \\
\text { personas con } \\
\text { VIH/SIDA }\end{array}$ & $\begin{array}{l}\text {-Aumento en el uso } \\
\text { del concepto "gay" } \\
\text {-Popularización y } \\
\text { difusión de } \\
\text { conocimientos sobre } \\
\text { VIH/SIDA } \\
\text {-Patologización de } \\
\text { conductas sexuales } \\
\text {-Visibilización de } \\
\text { parejas homoeróticas } \\
\text { "“Ghettos" } \\
\text { homosexuales: bares y } \\
\text { antros } \\
\text {-El SIDA se convierte } \\
\text { en una enfermedad } \\
\text { crónica y deja de } \\
\text { considerarse mortal }\end{array}$ \\
\hline
\end{tabular}

*Salinas Hernández, H.M. (2010), Políticas de Disidencia Sexual en América Latina: Sujetos sociales, gobierno y mercado en México, Bogotá y Buenos Aires. México, Ediciones Eón.

4 Para más detalles sobre los impactos subjetivos de los vaivenes del movimiento homosexual en México véase Lozano-Verduzco y Rocha, (2015). 


\begin{tabular}{|c|c|c|c|c|}
\hline $\begin{array}{l}\text {-Lucha contra } \\
\text { la homofobia } \\
\text { 2005-actualidad }\end{array}$ & $\begin{array}{l}\text {-Lucha por derechos } \\
\text { civiles y humanos }\end{array}$ & $\begin{array}{l}\text {-Reconocimiento a la } \\
\text { diversidad sexual } \\
\text {-Normalización de } \\
\text { identidades lésbicas } \\
\text { y gays }\end{array}$ & $\begin{array}{l}\text {-Aprobación de la } \\
\text { Ley Federal contra } \\
\text { la Discriminación } \\
\text {-Aprobación de la } \\
\text { Ley de Sociedades } \\
\text { en Convivencia } \\
\text { (DF) } \\
\text {-Modificación al } \\
\text { código civil del DF } \\
\text {-Amparos para } \\
\text { permitir matrimonio } \\
\text { entre parejas del } \\
\text { mismo sexo en } \\
\text { Sinaloa, Chihuahua, } \\
\text { Oaxaca, Yucatán, } \\
\text { Estado de México, } \\
\text { Colima y Estado de } \\
\text { México }\end{array}$ & $\begin{array}{l}\text {-Controversia Iglesia- } \\
\text { Estado } \\
\text {-Visibilización de } \\
\text { parejas del mismo } \\
\text { sexo } \\
\text {-Uso del espacio } \\
\text { público por parte de } \\
\text { comunidad } \\
\text { LGBTTTI }\end{array}$ \\
\hline
\end{tabular}

Esta división me permitió contextualizar el discurso de cada participante y encontrar la manera en que se relacionaban y/o subvertían los discursos hegemónicos de cada espacio cronológico a través de sus prácticas individuales o colectivas. La muestra quedó conformada de la siguiente forma: 
Tabla 2 Características socio-demográficas de los participantes

\begin{tabular}{|c|c|c|c|c|c|c|}
\hline Participante & Generación & Edad & $\begin{array}{l}\text { Lugar de } \\
\text { residencia }\end{array}$ & Ocupación & Nivel Educativo & $\begin{array}{c}\text { Ingresos } \\
\text { (pesos } \\
\text { mexicanos) }\end{array}$ \\
\hline Ramón & G1: 2012 & 20 años & $\begin{array}{l}\text { Atizapán de } \\
\text { Zaragoza, } \\
\text { Estado de } \\
\text { México }\end{array}$ & Estudiante & Licenciatura & Ninguno \\
\hline David & G1: 2008 & 22 años & $\begin{array}{l}\text { Atizapán de } \\
\text { Zaragoza, } \\
\text { Estado de } \\
\text { México }\end{array}$ & $\begin{array}{l}\text { Estudiante/empl } \\
\text { eado }\end{array}$ & Licenciatura trunca & Ninguno \\
\hline ED & G1: 2006 & 24 años & Ciudad Neza & Profesionista & Licenciatura & 7,000 \\
\hline Dante & G1: 2005 & 24 años & Coyoacán & $\begin{array}{l}\text { Profesionista/est } \\
\text { udiante }\end{array}$ & $\begin{array}{l}\text { Licenciatura } \\
\text { incompleta }\end{array}$ & 7,000 \\
\hline Alfonso & G1: 2011 & 19 años & Cuauhtémoc & Estudiante & $\begin{array}{l}\text { Licenciatura } \\
\text { incompleta }\end{array}$ & Ninguno \\
\hline Komadreja & G2: 2002 & 25 años & $\begin{array}{c}\text { Gustavo A. } \\
\text { Madero }\end{array}$ & $\begin{array}{l}\text { Estudiante/empl } \\
\text { eado }\end{array}$ & Licenciatura trunca & 2,500 \\
\hline Jorge & G2: 1991 & 51 años & Cuauhtémoc & Profesionista & Licenciatura & 40,000 \\
\hline Juan & G2: 1995 & 37 años & Cuauhtémoc & Empresario & Licenciatura & 34,000 \\
\hline Mario & G2: 1989 & 46 años & Cuauhtémoc & Profesionista & Maestría & 35,000 \\
\hline Javier & G2: 1990 & 40 años & $\begin{array}{c}\text { Gustavo A. } \\
\text { Madero }\end{array}$ & Profesionista & $\begin{array}{l}\text { Doctorado } \\
\text { incompleto }\end{array}$ & 30,000 \\
\hline Teo & G3: 1971 & 68 años & Iztapalapa & Jubilado & Licenciatura trunca & 20,000 \\
\hline Fernando & G3: 1983 & 46 años & $\begin{array}{l}\text { Álvaro } \\
\text { Obregón }\end{array}$ & Profesionista & Maestría incompleta & 15,000 \\
\hline César & G3: 1970 & 60 años & $\begin{array}{l}\text { Tultitlán, } \\
\text { Estado de } \\
\text { México }\end{array}$ & Profesor & Licenciatura & 8,000 \\
\hline Roberto & G3: 1976 & 52 años & Benito Juárez & Administrador & Licenciatura & 70,000 \\
\hline Hernán & G3: 1978 & 58 años & Cuauhtémoc & Músico & Licenciatura & $\begin{array}{c}\text { Sin } \\
\text { información }\end{array}$ \\
\hline
\end{tabular}


Entrevisté a profundidad a cada participante. Las entrevistas las realicé en dos sesiones diferentes, ya que esto me permitía distanciarme de su discurso, hacer un análisis inicial de cada entrevista y poder profundizar en aspectos que consideraba más relevantes durante la segunda sesión. Las entrevistas fueron realizadas en mi casa o en casa del participante y duraron entre 100 y 180 minutos. Todas fueron audiograbadas y transcritas fielmente.

Para analizar los datos, primero realicé un análisis línea por línea para identificar aspectos llamativos y códigos. Posteriormente, seguí un proceso de cristalización para formular las categorías de análisis que fueron llenadas con los códigos que resultaron del análisis línea por línea (Strauss y Corbin, 1994). Una vez identificada y saturada cada categoría, usé la perspectiva del Análisis Crítico del Discurso (ACD) (Ibáñez, 2003; Jager, 2003; Martín, 2003; Van Dijk, 2002 , 2011) para aproximarme a la forma en que ciertos discursos hegemónicos han sujetado o condicionado la vida de los participantes, así como la manera en que han podido deconstruir estos discursos, si es que lo han hecho (Jäger, 2003). Para Ibáñez (2003), el análisis del discurso es "un medio para llevar a la práctica el lenguaje a modo de eje de comprensión y estudio de los procesos sociales" (Ibáñez, 2003: $83)$, en el entendido de que las palabras son una forma de acción, en una dimensión interactiva, que constituye al sujeto y construye la realidad. Para Martín (2003), el ACD señala la manera en que cada sujeto interpreta y se posiciona ante los acontecimientos de sus contextos, lo cual obedece a su posición social, su grupo de pertenencia y los valores hegemónicos.

Además, usé principios de la Teoría Queer (Butler, 2006; Parrini, 2011; Preciado, 2002) para realizar el ACD de los datos que me proveyeron los entrevistados. Principalmente, me interesaba conocer la manera en que negociaban y hacían propios mandatos y normas del MMH y, sobre todo, si en sus significados y prácticas repetidas llegaban a un proceso de reflexividad y subversión como lo describe Butler (2006). Es decir, me interesaba analizar las formas en que los hombres se apropiaban de su noción de "hombre", "masculino", "gay" a través de la asunción de un deseo homoerótico, de prácticas políticas y de la ocupación del espacio público a partir de este deseo.

Para comprender de qué manera se puede hacer uso de estas nociones identitarias, me apoyé en los supuestos de Butler (2006), quien sostiene que la identidad es un proceso permanente en donde el sujeto repite (o itera) las normas sociales preexistentes. Es la encarnación de estas normas (a través de su repetición), lo que constituye nuestra identidad. Sin embargo, es la propia repetición de la norma lo que permite su (lenta) transformación, en un proceso que Butler (2006) nombra reflexividad. En tanto la iteración es una copia de la norma, nunca es igual a la norma original, y por tal, es la encarnación de la subversión. Si recordamos que para Preciado (2002) la Teoría Queer es una oposición radical a la norma y un cuestionamiento a la categorización identitaria, la reflexión sobre la incorporación de las normas en nuestra subjetividad implica un 
cuestionamiento a la hegemonía normativa que se expresa en actuaciones, performatividades y significados (Mamo, 2007).

Estas ideas y conceptos me permitieron mirar el uso del espacio público y los significados sobre el deseo como elementos que los hombres ponían en práctica para entender su identidad y su vida como libres de discriminación y violencia estructural. A pesar de que identificaban ser subordinados a las estructuras sociales resultantes de la heteronorma (Rubin, 1992; Warner, 1993) y del patriarcado (Amorós, 1992), los hombres buscaban, a través de prácticas políticas, formas de liberarse de ellas y sentirse libres en la vivencia de su deseo homoerótico y de su identidad. A esto le nombro prácticas políticas.

\section{RESULTADOS}

Basándome en análisis políticos en torno al movimiento "gay" mexicano y usando perspectivas de teóricas como Mouffe (1991) y Pateman (1996), colocar aspectos identitarios en lo público es, en el sistema político democrático, la única forma de hacer demandas al gobierno. Es decir, sólo cuando una persona se adscribe a una categoría identitaria, es posible ser beneficiario/a de los bienes y servicios públicos. De acuerdo con Pecheny y de la Dehesa (2010), las políticas públicas definen las posiciones que toma el Estado sobre su ciudadanía y son necesarias cuando existe algún asunto a tratar en alguna categoría de ciudadanos. En este sentido, el asunto "gay" u "homosexual" surge en México a finales de la década de los setenta, cuando inicia el movimiento gay. Desde entonces, dicho movimiento le ha venido presentando al Estado una serie de demandas para que las personas denominadas "lesbianas", "gay", "bisexuales" y "trans" sean beneficiarias de políticas públicas concretas y, por lo tanto, ciudadanos/as de pleno derecho. El esfuerzo de este colectivo por su reconocimiento cabal como ciudadanos ha sido compensado con políticas públicas de salud y de derechos civiles, por ejemplo con el cambio en el código civil del Distrito Federal en el 2010 que permitió el matrimonio y la adopción por parte de parejas del mismo sexo o las iniciativas de leyes que permiten que personas trans puedan cambiar su identidad legal (Vela, 2015).

Las cuestiones que afectan a la llamada diversidad sexual pueden ser innumerables: la variabilidad de identidades, facetas, formas de expresar el deseo y problemas, es prácticamente infinita. El contexto histórico-socio-político ha definido guiones en torno a la diversidad sexual, permitiendo cierto campo común para dar inicio al movimiento y a demandas consensuadas y claras. De acuerdo con Díez (2010), esto se ha facilitado por la construcción de una identidad colectiva, que ha empujado el mismo movimiento. En otras palabras, el sentido de una identidad colectiva entre la población gay es fundamental, pues es a través de ésta que se construyen y desarrollan políticas públicas que pueden garantizar la calidad de ciudadanos a este grupo. En pocas palabras, hay una estrecha relación entre las nuevas políticas públicas incluyentes, la noción de identidad gay que las ha inspirado y el deseo que la motiva (Lozano-Verduzco, 2015). 
Políticas públicas, identidad y deseo

El movimiento y la identidad gay se vuelven dos partes de un engranaje, pues la acción conjunta del movimiento incentiva la identidad colectiva y, a su vez, la apropiación de dicha identidad propicia la movilización. Esta dialéctica la expresa Alfonso:

[...] Iban a la marcha gay ¿no? Yo así de "¡ah! No pues yo no voy a ir ¿para qué voy si...?”, pero ahorita yo creo que ya como que sí, sí me considero parte de la comunidad gay [...] El estar saliendo y relacionarte con ese tipo de personas, te hace así como que pues... soy así ¿no? Me gusta ser así, y soy gay, entonces soy parte de esta comunidad (Alfonso, 19 años; Generación 1; estudiante).

La experiencia de Alfonso señala cómo la convivencia con otros hombres también definidos como gay, le permitió generar vínculos y formar una identidad personal y colectiva, debido al discurso gay que lo involucró en algunos aspectos del movimiento, como acudir a la marcha y apoyar en grupos de activismo. En otras palabras, poder ponerle un nombre a su deseo homoerótico implicó la posibilidad de entender que había otros que también se nombraban así y que llevaban a cabo ciertas prácticas, incluida la de asistir a la marcha del orgullo y la diversidad sexual. Identificarse como "gay" permite la entrada a grupos que antes eran desconocidos y a formar parte de sus actividades, algunas de las cuales implican el uso del espacio público. Retomando a Díez (2010), los conceptos de "homosexual" y "diversidad sexual" fueron fundamentales para el desarrollo de una identidad colectiva y, por tanto, del movimiento gay y del impacto que éste tuvo en el diseño de políticas públicas, ya que permitieron la convergencia de un gran grupo de personas en torno a una sola característica: la disidencia con la norma heterosexual.

De acuerdo con estas argumentaciones, el eslogan feminista (que también fue adoptado por el movimiento gay en México) "lo personal es político" se vuelve fundamental. Es decir, se requiere hacer público lo personal para que las necesidades y las peticiones particulares de la comunidad gay (históricamente, en condiciones de desigualdad en comparación con personas heterosexuales) lleguen a ser atendidas. Se requiere que los hombres, en cuanto individuos, lleven a cabo prácticas de visibilización, por ejemplo, vivir su sexualidad en lo público. Para muchos hombres, esto es sumamente complejo. Se trata de una petición casi imposible, pues el deseo, aunque cuestionado constantemente por la norma heterocéntrica, no está constituido por norma alguna. El trabajo de campo mostró que algunos hombres no desean hacer pública su orientación sexo-afectiva (OSA), pues sienten que puede tener efectos discriminatorios para ellos, especialmente en su trabajo y en su familia, por lo que es el propio discurso de homofobia lo que limita la actuación política de algunos participantes. La decisión de compartir y con quién compartir la intimidad es personal.

En los datos que encontré, algunos hombres de la segunda y la tercera generación fueron impactados por el discurso activista de la década de los ochenta y noventa y, por consiguiente, vivieron más abiertamente su deseo en comparación con los que no se inmiscuyeron en el activismo; muchos de los entrevistados de la segunda y la tercera 
generación no participaron en grupos de activismo y reportaron mayor temor a vivir su homoerotismo abiertamente y, por lo tanto, manejarse de manera clandestina. En cambio, sólo uno de los hombres de la primera generación participó activamente en el movimiento. Los hombres más jóvenes suelen vivirse sin temor a discriminación por vivirse abiertamente homoeróticos. Esto es un indicador de que la identidad colectiva de los noventa de la que habla Díez (2010) y el movimiento al cual le dio fuerza, ha mostrado efectos en nuevas generaciones de hombres gay. De cierta forma, las nuevas generaciones heredaron los efectos de la lucha que iniciaron hombres homosexuales hace décadas, resultando en la posibilidad de pensar en "salir del clóset" o no. Esta posibilidad no formaba parte de la experiencia de los hombres mayores.

El hecho de que los hombres jóvenes reproduzcan esta identidad colectiva gay a través de encarnar las posibilidades políticas por las que pelearon las primeras generaciones, significa que la transforman. En otras palabras, la forma de ser "gay" de los hombres de la segunda y tercera generación no es igual a la de los de la primera, pero es esta última la que retoma elementos anteriores para aterrizarlos en su día a día. Aunque los hombres más jóvenes se apropian de la categoría identitaria, la llenan de una forma distinta, un tanto más libre y flexiblemente. Es en estos pequeños cambios que observo la noción de reflexividad (Butler, 2006), pues se adoptan normas preexistentes a uno mismo para encarnarlas repetidamente con efectos diferentes a los anteriores.

Un ejemplo de la construcción de una identidad colectiva se puede ver en el uso del discurso de los hombres gay. Los hombres usan vocablos y conceptos que parecen ser únicos para la población LGBT. Por ejemplo, el uso de "ambiente", "la marcha", "jotear" y "buga", son conceptos que no requieren de explicación entre los hombres que entrevisté. Ellos aprenden su uso conforme se van inmiscuyendo con amistades y ambientes gay.

Pues por los mismos amigos ¿no? O sea es que "el ambiente”, y yo así “¿de qué ambiente hablas?”, este, y ya, pues ya me dijo, "no pues es que el ambiente, el ambiente gay". Se le llama así como ambiente. Entonces yo empecé así porque... pues términos ¿no? que van usando ese tipo de personas... bueno... Los gais y todo eso. Ya fue por eso que ya sé qué onda ¿no? (Alfonso, 19 años; Generación 1; estudiante).

Las narraciones expuestas son testimonio de que los elementos discursivos en torno a lo "gay" se usan de manera iterada y diferente en cada generación y por ello, la participación política en cada generación es distinta. Son los hombres de la tercera generación quienes llevaron a cabo prácticas políticas con mayor ahínco y con una clara vinculación con principios políticos de partidos de izquierda, a diferencia de los hombres de generaciones más jóvenes. Esto, por supuesto, tiene que ver con que los hombres de la tercera generación fueron socializados en la década de los ochenta, década en la que el movimiento gay mexicano comenzaba a ganar fuerza, se vivía una crisis económica nacional y el fin de la Guerra Fría en el ámbito global (Arguello, 2014; Laguarda, 2009). En la primera generación, interpreto un interés mucho menor por la participación política a través del activismo. Para los hombres más jóvenes, 
son suficientes los logros del movimiento gay y de los hombres de la tercera generación. Desde cierto punto de vista, la manera en que las diferentes generaciones salen del clóset, o no, frente a sus familias, influye en su mayor o menor activismo. En efecto, ese acto puede ser sumamente político, pues se trata de irrumpir en el orden familiar y sembrar la disidencia (Ahmed, 2010). Salir del clóset ante la familia es fundamental para los hombres de esta primera generación, pues al hacerlo consideran ejercer un acto político de gran impacto; los hombres de la primera generación demostraron tristeza y dolor por no poder hablar abiertamente de su deseo erótico y por no sentirse aceptados por sus padres. Mientras tanto, los hombres de mayor edad no consideraron importante sincerarse frente a la familia e inclusive eran sumamente cuidadosos de nunca hablar de ese tema frente a ella.

Con la solidificación de la identidad colectiva que describe Díez (2010), a partir de 1997 las demandas comenzaron a cambiar, pero ahora exigiendo igualdad de derechos civiles, como el matrimonio. A partir del trabajo de campo, pude observar que si bien estas peticiones se han cumplido en la Ciudad de México, ${ }^{5}$ los hombres siguen viviendo violencia y homofobia desde diferentes sectores, cuestión que sigue afectando su bienestar. A través de la lucha contra la homofobia, se logran modificar estructuras e

5 En el 2015, la Suprema Corte de Justicia de la Nación señaló como anti-constitucional prohibir el matrimonio entre dos personas, independientemente del sexo de los/as contrayentes. El 17 de mayo del 2016, unas semanas previas a la publicación de este texto, el presidente de la República Mexicana, Enrique Peña Nieto, anunció que producirían reformas constitucionales para garantizar el matrimonio y la adopción para parejas del mismo sexo. instituciones discriminatorias y opresivas. Con la reducción del estigma, es posible construir contextos que acepten y funcionen con una diversidad de formas sexo-genéricas, de cuerpos y de deseo (homo-eróticas, hetero-eróticas, bieróticas y demás erotismos aún no categorizados). Lo problemático es que las demandas del movimiento se han centrado en la adquisición de ciertos derechos, relegando a un segundo plano la lucha directa contra la homofobia (De la Dehesa, 2010; Díez, 2010; Salinas, 2010).

\section{Visibilidad}

La visibilidad que hacen los hombres de sí mismos como hombres homoeróticos (sea a través de identificarse "homosexual", "gay", etcétera), les permite entablar relaciones con la comunidad gay, así como adoptar recursos discursivos y lograr que se apropien de conceptos ya existentes para comunicarse y generar identidad. Es decir, estos vocablos son particulares para ciertos hombres $\mathrm{y}$, en ciertos espacios, se vuelven una forma de comunicación que permite identificar a aquellos hombres que son parecidos, que comparten un deseo homoerótico y que visibilizan su deseo. En otras ocasiones, la visibilidad que los hombres hicieron de sí mismos les permitió el acercamiento a grupos formados (generalmente activistas) de hombres gay lo que, a su vez, les llevó a identificar elementos, demandas, peticiones y problemáticas compartidas que agruparon bajo el nombre de "homosexual" o "gay", como identidad colectiva. Sobre todo en la segunda y tercera generación, encontré a hombres que por casualidad se toparon con manifestaciones, marchas o grupos 
organizados de hombres gay y al ver que se permitían expresar abiertamente su deseo, y que ese deseo homoerótico se compartía, los hombres comenzaron a sentirse parte de ese grupo.

No me identificaba [aún como homosexual], precisamente por todos estos prejuicios ¿no? Autorepresión. Pero cuando yo veo que hay un contingente que sale y sale a la luz y tal y se reivindican como homosexuales y lesbianas, además políticamente ¿no? Y yo estaba en grupos políticos y todo, entonces digo es que yo debo de estar ahí, ¿no? Yo debo de acercarme, ¿no? (Hernán, 58 años; Generación 3; profesionista).

A partir de observar a dos hombres besarse en un contexto de marcha política, Fernando, como otros entrevistados, es capaz de identificarse con ese deseo de encontrar a un grupo de referencia. Hernán, al ver a hombres y mujeres que portan con la etiqueta de homosexual, le permite iniciar un proceso de identificación, incluso de identificación política e iniciar un acercamiento físico a la comitiva. Otro de los entrevistados buscó grupos activistas en medios impresos y dio con uno de jóvenes, desde el cual pudo construir una red de amistad y de apoyo. La identidad colectiva "gay", permitió a ese grupo darse a conocer, para que otros hombres pudieran unirse a su causa. El movimiento gay ha sido una base desde la cual los hombres pueden comenzar a identificarse como parte de una comunidad, iniciar un estilo de vida particular, así como inscribir sus prácticas, ritos y significados en los símbolos identitarios y discursos producidos desde dicho movimiento. Una identidad que, en gran medida, es unificada a través del discurso. En efecto, la identidad y el movimiento gay han construido un discurso particular que unifica a los hombres bajo este término y que les permite entrar en diálogo con tomadores de decisiones para la generación de políticas públicas diseñadas e implementadas con perspectiva de "diversidad sexual".

En otros casos, este discurso permite que los sujetos tomen las riendas de la organización social para incidir en la dimensión política. Por ejemplo, Komadreja, que aunque de la segunda generación, por su edad, vivió los resultados del movimiento de los ochenta y noventa, se empapó del discurso de derechos e igualdad, lo que le permitió apropiarse de los vocablos "gay" y "homosexual" y convertirlos en su identidad. En su caso, le fue sumamente complejo conocer a otros hombres gay, por lo que recurrió a prácticas sexuales clandestinas con otros hombres en su universidad. Fue a través de estas prácticas que inició la convivencia afectiva y amistosa con otros hombres. Eso se transformó en un grupo organizado que ocupó espacios públicos de la universidad con el mensaje y las insignias gay. Este grupo es ahora muy conocido dentro de la universidad y dentro del movimiento gay de la ciudad.

Para mí nació en los baños del anexo, porque de repente con un güey, nos dimos cuenta que él conocía como a unos 20 y yo a otros 25 . No nos conocíamos entre todos. Y dijimos, pues somos tantos, aunque sea hay que juntarnos. Ahí ya nos enteramos que había un grupo virtual. Y ya, a partir de eso, el colectivo. Yo creo que el colectivo transformó radicalmente mi vida. Ahí conocí ahora sí, la jotería, como tal. Empecé a hablar más de los derechos, de las personas, de la población LGBTI. Es que... creó como un nuevo círculo social para mí (Komadreja, 25 años; Generación 2; estudiante). 
Éste es un claro ejemplo de cómo lo personal es verdaderamente político. El deseo de vinculación sexual, afectiva y amical con otros hombres también abiertamente homoeróticos, en conjunto con lo heredado por el discurso del movimiento gay, permite su continuación y la organización de grupos gay. El elemento que une a los sujetos en estos grupos, no es sólo el deseo erótico por personas de su mismo sexo ni la discriminación que se vive por ello, sino el deseo de vincularse con otras personas como ellos y de reivindicarse como sujetos políticos. Esto implica una vivencia compartida de segregación, discriminación y estigmatización que les permitió encontrar terreno común para organizarse.

Sin embargo, muchos hombres, a pesar de identificarse como gay u homosexuales, no se sienten parte de la comunidad o de la vida política gay. Muestran un discurso politizado, pero ellos no se viven como parte de la vida política, ni se incluyen en las demandas hechas por el movimiento gay actual. Para algunos hombres, el discurso político gay gira en torno al matrimonio y las uniones civiles, cuestión con la que algunos hombres no se sienten identificados. En otras palabras, encontré en su discurso y en sus experiencias la herencia del movimiento gay, la necesidad de avocar ciertos derechos, pero al mismo tiempo, ellos no se vivían como parte de la comunidad gay que demanda dichos cumplimientos. La separación de este grupo y de sus actividades también permite un alejamiento del discurso político propiamente gay; estos hombres se vivían como gay, pero su gaydad no cobraba la relevancia que cobraba para los hombres que sí forman parte de estos subgrupos.
Yo no me siento parte de un grupo de osos, ni de un grupo de musculosos, ni de un grupo activista radical, yo me siento como parte de alguien que comparte una sexualidad más amplia, con lazos, con afectos, que tiene derecho igual que toda otra persona independientemente de su orientación sexual, por ser ciudadano, por pagar impuestos, por vivir en un país, por tener libertades, por saber que estamos ahí, independientemente y esto es lo que me hace ir y hacer, y estar solidario, pero no como vivir o únicamente hacer mi vida dentro de la comunidad gay. Los problemas de la sociedad, es decir me siento adentro y no adentro, es una cosa rara, es una... (Javier, 40 años; Generación 2; profesionista).

El discurso de Javier apela a una definición amplia de ciudadanía, que toma en consideración las diferencias, gamas y diversidades de seres humanos. $\mathrm{Su}$ argumento es impactado por una visión de democracia producto de los Derechos Humanos, muy en boga en la década de los noventa (década donde Javier comenzó su inmersión en grupos políticos $\mathrm{y}$ activistas), que señala la igualdad para todos los seres humanos y su debido acceso a la ciudadanía. Esta noción la comparten varios hombres gay; son hombres que no desean ser catalogados públicamente como homosexuales, sino que buscan que su estatus de ciudadanía no se vea cuestionada por sus prácticas sexuales, su deseo y la manera en que lo ejercen. Como señala Parrini (2011), la narrativa oculta las grandes desigualdades, maltratos y discriminación de las cuales son objeto los hombres gay, orientado a pensar la igualdad "vaciada de cualquier contenido y tensión política" (Parrini, 2011: 1). Esto significa que esta narrativa olvida los maltratos y opresiones que viven los hombres gay. El discurso de la "igualdad", según Parrini, niega que existen diferencias y que 
estas diferencias estén basadas en un sistema heteronormativo y excluyente. Esto nos indica que el movimiento gay ha dejado a un lado los aspectos dolorosos y de malestar que afectan a su comunidad, para centrarse en demandas en torno a derechos civiles, particularmente, el matrimonio. De acuerdo con Meccia, este tipo de demandas obedece a las "políticas de reconocimiento" (Meccia, 2011: 84) que ha buscado el movimiento desde los noventa. Desde esta perspectiva, las uniones civiles son una forma de hacer visible a la comunidad gay. El matrimonio entre personas del mismo sexo ha permitido la visibilización de la comunidad gay, pero ha invisibilizado toda una serie de problemáticas que no se resolverán con el matrimonio igualitario, como la violencia, el estigma y sus efectos en las emociones, en la salud, en las relaciones de pareja, en las relaciones familiares y en la identidad misma.

Es este discurso "igualitario" el que ha sido consecuencia de la adopción de un discurso de Derechos Humanos acrítico y que en algún momento le dio fuerza al movimiento gay (Mogrovejo, 2008). Es decir, fue la perspectiva de Derechos Humanos durante la década de los noventa que fortaleció el movimiento, específicamente a través de la categoría de derechos sexuales y reproductivos (Díez, 2010), pero que hoy en día es usada de manera acrítica y que no permite vislumbrar los fuertes efectos de la homofobia cultural sobre la vida de la personas LGBTTTI (evidenciado en homicidios por odio y otras formas de discriminación). Sin embargo, como señala Parrini (2011), seguir asentándose en esta narración significa borrar y eliminar las diferencias en las cuales viven los hombres gay.
Continuar con este tipo de discursos es arriesgarse a olvidar las experiencias de dolor, tristeza, culpa, vergüenza y frustración de los hombres gay (Ahmed, 2010).

Algunos hombres entendían su vida política a través de las prácticas que realizaban y los lugares a los que acudían. Es a través de esto que lograban articular su identidad en torno a un colectivo y a una comunidad particular, la gay:

Por mi parte, yo, pues sí he difundido información cuando me lo solicitan amigos o conocidos, les digo dónde acercarse para hacer pruebas de VIH, cuando también tiene problemas, pues hacer esta labor como de acompañamiento. O, pues el grado de sensibilización que también se los trato de enseñar. Aunque no todos lo toman (ED, 24 años; Generación 1; profesionista).

Es que al final los antros son pues, pues diversión ¿no? Porque... ¿En qué parte sí me considero...? En que... en que pues, entiendo el, el, el que yo también soy gay y entiendo estar con personas gais y... ¡ay!, creo que ya enredé todo (David, 22 años; Generación 1; estudiante).

Los hombres articulan y tejen su realidad a partir de espacios que pueden compartir con otros hombres gay, como los centros nocturnos y, en menor medida, los ámbitos de acción política, como el activismo. Es importante tomar en cuenta que únicamente son los hombres que se autodenominan como "gay" o como "homosexual" los que articulan su identidad de esta forma. Existe amplia evidencia en México que señala que el deseo homoerótico no necesariamente se cristaliza en una identidad gay (Carrier, 2001; 
Núñez, 2009, Prieur, 2008) y que ésta es resultado de la interacción con ciertos contextos, como el urbano. Sin embargo, no todos los hombres se encuentran con estos espacios; muchos hacen una búsqueda proactiva por encontrarlos. En estos espacios, descubrí que hay un discurso que permite construir ideas y un discurso claro sobre demandas y problemáticas que viven los hombres gay. En cambio, en casos como el de David, la aproximación a espacios que son únicamente de esparcimiento, dificultan la articulación y construcción discursiva de la identidad, como se hace evidente en sus expresiones verbales. Lo que queda claro es que entre más alejados están los hombres de la vida "gay", es decir, alejados de los centros de esparcimiento, de reunión, de grupos organizados, de noticias y eventos políticos, menos cargan con un discurso de comunidad y se encuentran menos articulados con la identidad colectiva que se ha construido desde el movimiento. Debido a esto, yerguen una construcción centrada en sus necesidades personales, como es el caso de Dante:

No, no; yo lo que veo digamos, por encima, lo que es la comunidad gay lo veo muy superficial; lo veo mucho así todas loquitas bailando canciones de Thalía, que nada más se la pasan de antro en antro, yendo a marchas — ni siquiera me interesa ir a marchas, no me identifico con eso... A mí lo único que me interesa es lo personal, o sea lo que a mí me concierne... (Dante, 24 años; Generación 1; estudiante).

Al mismo tiempo, Dante me platicó de su deseo de casarse, tener hijos y formar una familia, cosa que compartía con algunos otros hombres de su generación. Su experiencia sugiere que la distancia entre él y la comunidad gay le dificulta mirar sus necesidades personales como parte de demandas y asuntos de todo el colectivo LGBT. Sin embargo, varios hombres de la generación dos y tres, particularmente por encima de los 45 años, me comentaron que pocas veces se habían cuestionado la idea de casarse o tener hijos y, si lo llegaron a hacer, asumían que debido a su deseo homoerótico, esto no era posible (Lozano y Jiménez, 2010). Si bien las nuevas generaciones y los hombres gay más jóvenes pueden incorporar en su proyecto de futuro una idea de vida en familia, en realidad, se trata de una visión producida a partir de un modelo heterosexista.

\section{Matrimonio y familia}

Activistas en México y en otras latitudes han argumentado que lograr el matrimonio igualitario permite la visibilización de la población gay, al colocar la igualdad de este grupo en la agenda pública. Sin embargo, es importante preguntarnos: ¿cuál es el costo de este ejercicio? Si bien el discurso de la mayoría de los participantes que entrevisté tiene un cierto grado de politización gracias a esta visibilidad, se trata de un pensamiento poco crítico que se olvida de las condiciones opresoras en las cuales se sitúa el matrimonio. No puedo evitar preguntarme si las reformas al código civil de la Ciudad de México - y algunas otras ciudades(Vela, 2014), para permitir el matrimonio entre personas del mismo sexo y la adopción de niños/ as por parejas homosexuales, es una forma de 
"queerar" las instituciones y las normativas o simplemente una forma de heteronormalizarse.

El matrimonio fue, hasta 2010, una institución de la cual las personas homoeróticas estaban excluidas y es posible que debido al matrimonio igualitario, las fronteras entre inclusión y exclusión se volvieron más porosas y permitió a las parejas del mismo sexo tener acceso a ciertos derechos. Sin embargo, ahora las parejas del mismo sexo pueden ser incluidas en el sistema normativo que pensó y creó al matrimonio, un sistema que borra, olvida y esconde "realidades permanentes de discriminación, no-reconocimiento y violencia" (Ahmed, 2010: 1769 [versión Kindle]). Permitir las uniones civiles entre personas del mismo sexo, según Ahmed, es una manera de volverse "aceptable" en un mundo "que ya ha decidido qué es aceptable". ${ }^{7}$ Esto significa que las instituciones no se pueden "queerar" o transformar. Halperin (2009) concuerda, al retomar a Foucault, pues señala que las nuevas luchas políticas y nuevas dinámicas sexuales resultan en nuevas formas de constreñir y naturalizar la normatividad sexual. Pero en el esfuerzo por visibilizarse, el movimiento no puede crear nuevos horizontes de inteligibilidad personal y colectiva, o imaginar otras formas de vida y de relaciones sociales justamente porque las políticas de igualdad son políticas de normalización (Parrini, 2011).

Así, el matrimonio entre personas del mismo sexo ha podido ser visto como una estrategia para

6 Uso "queerar" de manera similar al verbo anglosajón "to queer" que se refiere a volver un objeto "queer" o "disidente", o en palabras de Beatriz Preciado "torcerlo" (Preciado, 2002). Es decir, encontrar una lógica diferente a la existencia de ese objeto.

7 Traducciones del autor. normalizar a la disidencia. El fin del proyecto gay en México ha sido la mímesis, la reproducción y la repetición del sistema heteronormal. En esta mímesis, el movimiento gay hace una especie de pacto con el Estado, se articula con él y desde ese poder se define de qué manera puede ingresar la diversidad sexual a la realidad socio-política.

Esto se hace evidente cuando, como sugiere Mamo (2007), volvemos la mirada al significado que se le atribuye al matrimonio. Uso un extracto del único entrevistado que estaba casado al momento de entrevistarlo:

Digamos que tenga un reconocimiento social, el matrimonio ¿no? El estar casado pues no es lo mismo a "ah, mi pareja" o "ah, mi novio"... Te digo, para mí realmente que tengamos firmado un papel, no signifique que esté más comprometido o menos comprometido. Estamos reconocidos como una pareja y puedo hacer uso también de los beneficios. Pero, no es que yo tenga mayor compromiso con él, o sea lo tendría de igual manera si estuviéramos casados o no (Juan, 37 años; Generación 2; empresario).

Juan, al casarse, se adscribe al significado legal de matrimonio, un significado único que aplica para todas las personas que desean ingresar a esta institución. Sin embargo, Juan y su pareja atribuyen un significado particular a su relación matrimonial, pues "no cambia mi compromiso", además de que viven en una relación abierta que permite explorar nuevas y otras relaciones eróticas y sexuales con otros hombres que no están incluidos en su acuerdo matrimonial. En este sentido, Juan y su pareja han seguido la vía de su deseo. Seguir el camino del deseo no sólo depende del significado atribuido al 
mismo, sino además de las prácticas vinculadas a ella. Al hacer esta "burla" del matrimonio, repiten la institución sin caer en la mímesis, sino que transgreden las normas mismas de la institución matrimonial al darle una forma propia al amor y al deseo que los constituyó pareja. En este sentido, la vía del reconocimiento, a través de la demanda de derechos "igualitarios", regula el deseo. Una política igualitaria permite la visibilidad de la identidad y de la comunidad gay, pero a costa de congelar la heterogeneidad, de heteronormalizar el deseo que ha sido entendido como anormal y sin permitirle una forma libre de expresión y vivencia. Juan se escapa de esta heteronormalización debido al significado que le atribuye a su matrimonio y a su deseo, y a las prácticas que adopta en consenso con su pareja, prácticas que rompen con el principio de monogamia de la heternormatividad identificado por Rubin (1992).

Poner el deseo como eje articulador de la identidad política fue muy poco común entre los entrevistados. Sin embargo, lo detecté en por lo menos dos de ellos que, curiosamente, tenían experiencias de activismo.

Yo hablaría de una reivindicación y de una confirmación. Soy realmente homosexual porque mi sexualidad funciona a partir de otro hombre. Y saber que yo soy esto ¿no? Es como tener la conciencia de lo que soy, y actuar en consecuencia ¿no? Si yo soy homosexual y además tengo una conciencia social y política, oye, pues con mayor razón voy a exigir derechos, somos nosotros que tenemos el derecho de hablar de nuestra propia sexualidad (Hernán, 58 años; Generación 3; profesionista).
El discurso de Hernán gira en torno a una vindicación del homoerotismo. Sus palabras dejan ver la importancia de la visibilidad, pero sin especificar la vía que esta visibilidad debe de tomar. También señala la opresión vivida por grandes instituciones sociales, instituciones que han opacado y oprimido de una u otra forma al homoerotismo y a formas no heterocentradas de deseo. El cuerpo, sus expresiones y la interpretación del deseo a través de éste son el eje que articula la vida política y activista. El deseo es el que se tiene que vindicar y el obstáculo principal son las instituciones que lo norman. El medio para realizar esto es la voz: hay que "hablar", hablar del deseo, de la sexualidad y del cuerpo. Es en este sentido que para muchos lo público y la visibilidad se vuelven fundamentales. Lo que a estos participantes se les escapa es que las normas que dan lugar a las instituciones, no sólo norman al deseo sino que le dan lugar a su existencia.

\section{Homosexual vs. Gay: sus transformaciones}

La categorización es algo que atraviesa a las tres generaciones. Los hombres definen a la gaydad y la homosexualidad principalmente por su deseo; es decir, su deseo los lleva a ser "gay" u "homosexual". El ser gay u homosexual permite vincularse de cierta forma, relacionarse en ciertos espacios e incorporar significados y prácticas particulares a la sensación de identidad. Son estos elementos los que posibilitan la expresión del deseo homoerótico.

Pues gay porque me gustan los hombres y ya (Roberto, 51 años; Generación 3; empresario). 
Es que no entiendo muy bien como la diferencia entre gay y homosexual... Este..., pus... es que no sé, o sea... sí [puedo definirme con ambas palabras]. Ajá. (Ramón, 20 años; Generación 1; estudiante).

En cambio, otros entrevistados expresaron un discurso claro y contundente que cuestiona esta forma simplista de entender la gaydad y la homosexualidad. Esta postura la reflejaron los activistas; en particular, Komadreja, un activista universitario. $\mathrm{Su}$ narrativa me parece que es producto de su interacción con otros jóvenes universitarios y con académicos de su universidad que han producido conocimiento sobre estas dos categorías. De esta forma, existe una tendencia un tanto crítica, sobre todo desde los activistas, que cuestiona la homosexualidad entendida únicamente como deseo.

Ser homosexual, como tal, es, digamos, cualquier hombre que se sienta atraído sentimental y sexualmente a otro hombre. Y también para mujeres. Pero creo que sí, ser gay implica toda una forma de ser, de ver la vida. Yo creo que el ser gay implica que viva en la ciudad, yo creo que por eso soy gay. Por qué, por la forma en que llevo mi vida, la forma en que llevo mi sexualidad. Yo me asumo como gay... Para mí, pues sí, es como ser consciente de que no es algo malo, inclusive el ser gay es, pues no sé, un poco el estilo de vida... El hecho de, para empezar, sí estar estudiando, yo creo que el hecho de repente ir a eventos culturales, ir a teatros, ir a eventos, ir a museos, creo que... es cierto nivel educativo y cultural... El ser gay es como... un caso particular de la homosexualidad, o una forma particular de ser homosexual. Yo creo, como una identidad, dentro de la homosexualidad. (Komadreja, 25 años; Generación 2; estudiante).
La aseveración de Komadreja muestra lo que algunos investigadores ya han señalado: lo gay marca un estilo de vida, no sólo por el deseo sino por la clase (Laguarda, 2009; List, 2005; Uribe y Arce, 2005), el acceso a recursos simbólicos como educación y espacios culturales que permiten integrar elementos de reflexión a la identidad. Desde esta visión académica, en efecto, la gaydad es una forma de ser homosexual, mientras que la homosexualidad señala hacia dónde se orienta el deseo. Este tipo de discurso cuestiona la idea de homosexualidad como patología y genera una categoría que permite a ciertos hombres homoeróticos identificarse a sí mismos, específicamente a los que se nombran activistas. Este proceso de identificación implica llevar a lo público el deseo que cuestiona constantemente el binomio bueno-malo en el cual se concibe la homosexualidad. Lo gay es político: constituye una forma de ser crítico ante las normas heterosexuales.

Fernando me describió el "estilo de vida" gay de su juventud. Señaló que el ser gay tenía impactos políticos; se trataba de una categoría identitaria a través de la cual los hombres podían vindicarse y encontrar valor en sí mismos. Fernando habla de principio de los años noventa, cuando la categoría gay tomó fuerza y se fue construyendo, por lo que señala cierta segregación y separación que él y sus amigos vivieron basada en el deseo y en la identidad. Esta categorizaciónsegregación era necesaria en ese momento para establecer los límites de la identidad, los espacios que ocuparía y las dinámicas que provocaría. 
Pues el homosexual para mí tenía una connotación política, pero, no siempre comulgaba con toda la vida gay que había. Para mí lo gay era esos chavos de esos espacios que nada más se movían ahí que no salían de ahí y que toda su vida amorosa, familiar, sentimental, la hacían en esos espacios [los antros]. Había mucha frivolidad... No había tanta solidaridad... Había mucha clasificación y mucha etiquetación ¿no? Había muchas prácticas discriminatorias, muy, muy fuertes. Incluso yo creo que lo gay ha empezado a difuminarse pues, ¿no? Ya no es una identidad o una categoría tan dura como era antes... Porque aquel cuate que se definiera bisexual, para muchos decíamos "es que es un gay encubierto" y efectivamente, si quería interactuar con nosotros, sí tenía que definirse como gay y si no se definía era una agresión constante: "closetera, closetera, closetera, hipócrita, pinche cobarde, maricona." Si llegábamos a enterarnos que tenía relaciones con chavas, puta, "traidora"; era en verdad, era una ejecución muy ojete. Sí, hace años era muy, muy rígido y era rígido, era violento, además. (Fernando, 46 años; Generación 3; profesionista).

Fernando muestra cómo la interacción individual y colectiva va construyendo una identidad. En este caso, la identidad gay se presenta como una que clausura, que prohíbe un deseo heteroerótico. El deseo que no era única y exclusivamente homoerótico era violentado y segregado; se llevaba a cabo un proceso de ostracismo hacia la persona que no cumplía con ciertos estándares. La identidad gay no sólo se construye en torno al deseo, sino al estilo de vida y a la manera en que consume el mercado: los lugares a donde acude, la ropa que viste, las bebidas que toma, la música que disfruta, etcétera. A pesar de las clausuras que la identidad gay representa, la experiencia de los hombres de generaciones más grandes señala que la categoría se ha transformado y se ha vuelto porosa, permitiendo un poco más el movimiento y la liquidez del deseo.

\section{COMENTARIOS FINALES}

La identidad gay se encuentra en una posición tensa y contradictoria. El deseo homoerótico, que termina siendo regulado por instituciones sociales como el matrimonio, tiene lugar gracias a esas mismas instituciones, pues, recordando a Foucault (1978), el deseo sólo tiene sentido dentro del discurso. La identidad gay, bajo esta lógica, es una identidad que normaliza, pues busca ser parte del sistema heterocentrista, al ser reconocido por éste. No obstante, conformarse con esta visibilización del deseo homoerótico sólo a través de la identidad gay y del matrimonio implica ignorar las violencias de las cuales son objeto los hombres gay en su vida cotidiana. Dicha violencia tiene efectos importantísimos sobre la salud ${ }^{8}$ (Mendoza, Ortíz, Román y Rojas, 2015). ¿Vale la pena poner en riesgo el bienestar y la salud por esos procesos de normalización de la gaydad y el deseo homoerótico, o existe la posibilidad de generar otros caminos y otros espacios simbólicos que cuestionen y mantengan tensión de una forma que no sea a costa del malestar emocional?

A pesar de que el movimiento gay logró construir una identidad colectiva a través de la cual llevó a cabo sus demandas y de que la identidad colectiva ha tenido su propio proceso reflexivo,

8 Por ejemplo, mayores probabilidades de ideación e intento suicida, síntomas depresivos y ansiosos y abuso de alcohol y otras drogas. 
mostrado en los cambios entre generaciones, escoger la vía de la identidad implica, de algún modo, escoger el camino de la homogeneidad. La identidad forzosamente implica homogeneidad, pues para poder entablar un diálogo con el Estado y con el mismo movimiento, los hombres deben etiquetarse bajo el nombre de "gay". Por eso, algunos de los hombres que entrevisté no se miran como parte de esa comunidad, no se identifican con las expresiones públicas de quienes participan en el movimiento, o no se identifican con los gustos y con el mercado que ha afectado a la cultura gay. Estos son indicios de que el homoerotismo y quienes se nombran "gay", no son homogéneos. Por el contrario, el deseo es heterogéneo, no se cristaliza, ni se congela. El movimiento gay ha producido una identidad colectiva que, en su oportunidad, ha provocado la creación de políticas públicas de efectos paradójicos: limitar el deseo erótico, como lo hace cualquier otra categoría identitaria. Esas políticas públicas empujan a los hombres homoeróticos de la Ciudad de México a nombrarse bajo este nuevo sujeto político de la "diversidad sexual" que, irónicamente, en ocasiones no ha reconocido esa diversidad y que alcanza en su mayoría a hombres de clase media y de zonas urbanas (Lozano-Verduzco y Rocha, 2015; Vargas, 2015).

En este esfuerzo de heteronormalización, el movimiento gay ha dejado a un lado la violencia, la discriminación y el estigma vivido por los hombres gay y homoeróticos. Es esta violencia homofóbica la que tiene efectos importantes sobre las emociones y la salud de los hombres y hacia dónde tendrían que enfocarse las políticas públicas de la "diversidad sexual". El camino de la identidad y de la normalización tiene implicaciones en el bienestar emocional de los hombres y sobre a quiénes considera sujetos políticos. Propuestas como las de Ahmed (2010), Butler, (2006) y Halperin (2009) señalan que la violencia homofóbica constante, producto del sistema heteropatriarcal no permite que las víctimas de dicha violencia se apropien de los derechos que la ley les otorga y permite que las víctimas sean percibidas como "menos" ciudadanos que otros, con menos valía que otras identidades. Aquellos que no encajan en esta heteronormalización, no entran en la categoría de sujetos que ha propuesto el mismo movimiento que intenta reconocerlos, por una razón muy simple: no reconoce el carácter fluido del deseo. Los asuntos del deseo y del estigma son los que deben de estar al centro de la "diversidad sexual", porque de esta forma se reconoce el deseo de todo sujeto (hetero, bi, homo, etcétera) y la subordinación de los heteronormales frente a otros. əo

\section{AGRADECIMIENTOS}

El autor agradece la lectura crítica y las aportaciones del Mtro. Ignacio Lozano Moheno y la guía del Mtro. Rodrigo Parrini Roses. 


\section{BIBLIOGRAFÍA}

Ahmed, Sarah (2010), The promise of happiness. London, Duke University Press. [Versión Kindle]

Amorós, Celia (1992), "Notas para una teoría nominalista del patriarcado", en Asparkía. Investigació Feminista, núm. 1, pp. 41-58.

Argüello, Sofía (2014), "Identidades en disputa: discursos científicos, medios de comunicación y estrategias políticas del Movimiento de Liberación Homosexual mexicano, 1968-1984”, en Rodrigo Parrini y Alejandro Brito (coords.), La memoria y el deseo. Estudios gay in Queer en México. México, PUEG, pp. 25-49.

Blumer, Herbert (1998), Symbolic interactionism, perspective and method. New Jersey, Prentice Hall.

Butler, Judith (2006), Deshacer el género. México, Paidós.

Careaga, Gloria (2004), “Orientaciones Sexuales. Alternativas e Identidad”, en Gloria Careaga y Salvador Cruz (coords.), Sexualidades Diversas. Aproximaciones para su análisis. México, Miguel Ángel Porrúa, PUEG, pp. 171-188.

Carrier, Joseph (2001), De los otros: intimidad y comportamiento homosexual del hombre mexicano. Madrid, Talasa Ediciones.

Connell, Raewyn y James Messerschmidt (2005), "Hegemonic masculinity: Rethinking the concept", en Gender and Society, vol. 19, núm. 6, pp. 829-859.

De la Dehesa, Rafael (2010), Queering the public sphere in Mexico and Brazil: Sexual rights movements in emerging democracies. London, Duke University Press.

Díaz-Loving, Rolando, Tania Esmeralda Rocha y Sofía Rivera (2007), La instrumentalidad y expresividad desde una perspectiva psico-socio-cultural. México, Miguel Ángel Porrúa, UNAM.

Díez, Jordi (2010), “The importance of policy frames in contentious politics: Mexico's National Antihomophobia Campaign”, en Latin American Research Review, vol. 45, núm. 1, pp. 33-54. 
Flick, Uwe (2004), Introducción a la investigación cualitativa. Madrid, Ediciones Morata.

Foucault, Michel (1978), The history of sexuality, an introduction, Volume I. New York, Vintage Books.

García, Miguel, Magdalena Andrade, Ricardo Maldonado y Claudia Morales (2009), Memoria de la lucha contra el VIH en México. México, CONAPRED.

Granados, José Arturo y Guadalupe Delgado (2007), Salud mental y riesgo de VIH-SIDA en jóvenes homosexuales. Aproximación cualitativa a la experiencia de la homofobia. México, UAM.

Halperin, David (2009), What do gay men want?: An Essay on Sex, Risk, and Subjectivity. Ann Arbor, The University of Michigan Press.

Íñiguez, Lupicinio (2003), "El análisis del discurso en las ciencias sociales: variedades, tradiciones y práctica”, en Lupicinio Íñiguez (ed.), Análisis del discurso: manual para las ciencias sociales. Barcelona, Editorial UOC, pp. 83-123.

Jäger, Siegfried (2003), "Discurso y conocimiento: aspectos teóricos y metodológicos de la crítica del discurso y del análisis de dispositivos", en Ruth Wodak y Michael Meyer (comps.), Métodos de Análisis Crítico del Discurso. Barcelona, Gedisa, pp. 61-100.

Kimmel, Michael (2008), Guyland, the perilous world where boys become men. New York, Harper.

Laguarda, Rodrigo (2009), Ser gay en la ciudad de México. Lucha de representaciones y apropiación de una identidad, 1968-1982. México, CIESAS/Instituto Mora.

List, Mauricio (2005), Jóvenes corazones gay de la Ciudad de México. Puebla, BUAP.

List, Mauricio (2009), Hablo por mi diferencia, de la identidad gay al reconocimiento de lo queer. México, Ediciones Eón, Grupo de Estudios sobre Sexualidad y Sociedad, Cuerpo Descifrado, Fundación Arcoiris.

Lozano-Verduzco, Ignacio y Alina Jiménez Solórzano (2010), "La homoparentalidad desde gays y lesbianas en la Ciudad de México", en Revista Digital Universitaria, vol. 11, núm. 8, pp. 3-16. 
Lozano, Ignacio y Tania Esmeralda Rocha (2011), "La homofobia y su relación con la "masculinidad" hegemónica en México", en Revista Puertorriqueña de Psicología, vol. 22, pp. 101-120.

Lozano-Verduzco, Ignacio (2015), "Desire, emotions and identity of gay men in Mexico City", en Psychology of Men \& Masculinity, vol. 16, núm. 4, pp. 448-458.

Lozano-Verduzco, Ignacio y Tania Esmeralda Rocha (2015), “Analysis of the category 'gay identity': situated knowledge in Mexico", en Psychology of Sexualities Review, vol. 6, núm. 1, pp 56-73.

Mamo, Laura (2007), “Queering Reproduction: Achieving pregnancy in the Age of Technoscience. NC, Duke University Press.

Martín Rojo, Luisa (2003), "El análisis crítico del discurso. Fronteras y exclusión social en los discursos racistas”, en Lupicinio Íñiguez (ed.), Análisis del discurso: manual para las ciencias sociales. Barcelona, Editorial UOC, pp. 157-191.

Meccia, Ernesto (2011), La cuestión gay. Un enfoque sociológico. Buenos Aires, Gran Aldea Editores.

Mendoza, Juan Carlos, Luis Ortíz, Ricardo Román y Aarón Rojas (2015), Principales Resultados del Diagnóstico situacional de personas lesbianas, gays, bisexuales, transgénero, travestis, transexuales, intersexuales y queers (LGBTIQ) de México 2015. México, UAM-Xochimilco, Inspira Cambio AC.

Mogrovejo, Norma (2008), "Diversidad sexual, un concepto problemático", en Revista trabajo social, núm. 18, pp. 62-72.

Monsiváis, Carlos (1998), "El mundo soslayado (Donde se mezclan la confesión y la proclama)", en Salvador Novo, La estatua de sal. México, Consejo Nacional para la Cultura y las Artes, pp. 11-41.

Mouffe, Chantal (1991), "Democratic Citizenship and the Political Community", en Community at Loose Ends. Minnesota, Miami Theory Collective, University of Minnesota Press, pp. 70-82.

Núñez Noriega, Guillermo (2000), Sexo entre varones: poder y resistencia en el campo sexual. México, Miguel Ángel Porrúa, PUEG. 
Núñez Noriega, Guillermo (2005), Diversidad sexual y afectiva, un nuevo concepto para una nueva democracia. México, Mimeo.

Núñez Noriega, Guillermo (2009), Vida vulnerables: hombres indígenas, diversidad sexual y VIH-SIDA. México, Edamex, CIAD.

Parrini, Rodrigo (2011), Políticas híbridas: Mímesis, justicia y abyección en los colectivos minoritarios, consultado el 11 de julio de 2013, URL: http:/www.equidad.scjn.gob.mx/biblioteca_virtual/ GeneroDerechoYJusticia/09.pdf

Pateman, Carol (1996), "Crítica feministas a la dicotomía público/privado", en Carme Castells (ed). Perspectivas feministas en teoria politica. Barcelona, Paidós Ibérica, pp. 31-52.

Pecheny, Mario y Rafael de la Dehesa (2010), Sexualidades y políticas en América Latina: un esbozo para la discusión, consultado el 11 de julio de 2013, URL: http://www.sxpolitics.org/pt/wp-content/ uploads/2009/10/sexualidades-y-politicas-en-america-latina-rafael-de-la-dehesa-y-mario-pecheny.pdf

Preciado, Beatriz (2002), Manifiesto contra-sexual. Prácticas subversivas de identidad sexual. Madrid, Ópera Prima.

Prieur, Annick (2008), La casa de la Mema, travestis, locas y machos. México, PUEG-UNAM.

Pujal i Llombart, Margot (2004), "La identidad (el self)", en Tomás Ibáñez (coord.), Introducción a la Psicología Social. Barcelona, Editorial UOC, pp. 93-137.

Rubin, Gayle (1992), "Thinking Sex: Notes for a Radical Theory of the Politics of Sexuality", en Carol S. Vance (ed.), Pleasure and Danger: Exploring Female Sexuality. London, Pandora, pp. 267-293.

Salinas Hernández, Héctor Miguel (2010), Políticas de Disidencia Sexual en América Latina. Sujetos sociales, gobierno y mercado en México, Bogotá y Buenos Aires. México. Ediciones Eón.

Strauss, Anselm y Juliet Corbin (1994), Bases de la investigación cualitativa. Técnicas y procedimientos para desarrollar la teoría fundamentada. Medellín, Editorial Universidad de Antoquia.

Tena Guerrero, Olivia (2007), "Problemas afectivos relacionados con la pérdida, disminución y riesgo 
de pérdida del empleo en varones", en Olivia Tena y Lucero Jiménez (eds.), Reflexiones sobre masculinidades y empleo. Morelos, UNAM, Centro Regional de Investigaciones Multidisciplinarias, pp. 357-375.

Unger, Rhoda (2000), "Outsiders Inside: Positive Marginality and Social Change”, en Journal of Social Issues, vol. 56, núm. 1, pp. 163-179.

Uribe, Raúl y Adrián Arce (2005), "Subiendo Escalones: Reflexiones a partir del trabajo grupal con adolescentes gay", en Subjetividad y Género. Revista de Psicología de la UAM-X. VII. (Enero), pp. 137-149.

Van Dijk, Teun (2002), “Critical Discourse Studies: A Sociocognitive Approach”, en Ruth Wodak y Michael Meyer (eds.), Methods of Critical Discourse Analysis. London, Sage, pp. 95-120.

Van Dijk, Teun (2011), Sociedad y Discurso. Barcelona, Gedisa.

Vela, Estefanía (2014), “Same-Sex Unions in Mexico: Between Text and Doctrine”, en Macarena Sáez (ed.), Same Sex Couples - Comparative Insights on Marriage and Cohabitation. Washington, Springer, pp. 49-83.

Warner, Michael (1993), “Introduction”, en Michael Warner (ed.), Fear of a Queer Planet. Queer Politics and Social Theory. Minneapolis, University of Minnesota Press, pp. 7-31.

Fecha de recepción: 10 de diciembre de 2015

Fecha de aceptación: 26 de mayo de 2016

\section{ACERCA DEL AUTOR}

\section{IGNACIO LOZANO-VERDUZCO}

(ilozano@upn.mx)

Es doctor en psicología por la Universidad Nacional Autónoma de México y profesor de tiempo completo en la Universidad Pedagógica Nacional. Sus líneas de investigación se centran en el estigma y discriminación y sus efectos sobre la subjetividad y la salud, específicamente la discriminación por orientación sexual y su impacto en las identidades LGBT. Sus dos más recientes publicaciones son 
"Desire, emotions and identity of Gay Men in Mexico City", en Pyschology of Men \& Masculinity (2015) $\mathrm{y}$ "Experiences of Power and Violence in Mexican Men Attending Mutual-Aid Residential Centers for Addiction Treatment", en American Journal of Men's Health (en coautoría, 2015). 